\title{
El combate fecundo: Aron frente a Marx y el izquierdismo
}

\author{
The prolific combat: Aron against Marx and leftism
}

\section{Sergio Morresi}

CONICET / Instituto de Humanidades y Ciencias Sociales del Litoral - Universidad Nacional del Litoral, Argentina smorresi@gmail.com

\author{
Martin Vicente \\ CONICET/ Instituto de Geografía, Historia y Ciencias Sociales-Universidad Nacional del Centro de la Provincia de \\ Buenos Aires (IGEHCS-UNCPBA), Argentina \\ vicentemartin28@gmail.com
}

\begin{abstract}
Resumen:
El objetivo de este artículo es mostrar que el debate entre Raymond Aron y los izquierdistas franceses como Jean-Paul Sartre y Maurice Merleau-Ponty no fue apenas una expresión de la guerra fría ni una diatriba liberal doctrinaria contra el socialismo, sino un combate intelectual acerca de los modos de leer a Marx. En este sentido, se muestra que, contra algunas perspectivas de mediados del siglo XX que buscaron mostrar a un Marx hegeliano, sansimoniano o economicista, Aron sostuvo que el "marxismo de Marx" debería interpretarse considerando la economía política del pensador de Tréveris a la luz de su filosofía de la historia. Con base en esta lectura -que contenía una mirada heterodoxa sobre algunos conceptos clave del marxismo como la alienación y la tendencia decreciente de la tasa de ganancia- Aron ensayó una severa crítica de los pensadores izquierdistas, quienes se postulaban como intelectuales independientes del Partido Comunista pero condonaban las posturas de la Unión Soviética en nombre de una liberación humanista que, desde la perspectiva aroniana, estaba basada en una lectura frívola o errada de los textos marxianos.

PALABRAS CLAVE: Marxismo, Izquierda francesa, Intelectuales.
\end{abstract}

\section{Abstract:}

The purpose of this article is to show that the debate between Raymond Aron and the French leftist like Jean-Paul Sartre and Maurice Merleau-Ponty was not just an expression of the cold war nor a doctrinaire liberal diatribe against socialism, but an intellectual battle about the ways of reading Marx. In this sense, it is shown that, against some perspectives of the mid-twentieth century that sought to show a Hegelian, Sansimonian or economicist Marx, Aron argued that the "Marxism of Marx" should be interpreted considering the political economy of the Trier thinker under the light of his philosophy of history. Based on this reading - which contained an unorthodox look at some key concepts of Marxism such as alienation and the declining trend of the rate of profit - Aron rehearsed a severe critique of leftist thinkers, who posited as independent intellectuals of the Communist Party but they condoned the positions of the Soviet Union in the name of a humanist liberation that, from the Aronian perspective, was based on a frivolous or erroneous reading of the Marxian texts.

KEYWORDS: Marxism, French Left, Intellectuals.

\section{INTRODUCCIÓN}

Raymond Aron ocupa un sitial destacado en el panteón liberal, lugar que ganó pugnando por un liberalismo plural y moderado con la convicción del militante, la meticulosidad del estudioso y la voluntad polémica del intelectual. La posición de Aron no puede explicarse sólo apelando a la tradición doctrinaria francesa ni reducirse a la expresión de un ethos determinado, como el de los debates de la guerra fría. La obra y la trayectoria de Aron cobran pleno sentido cuando se resalta una cuestión que en ocasiones se pasa por alto ${ }^{1}$ : que él concebía su formación y sus convicciones como consecuencias de una lectura sistemática y a la vez escéptica de Karl Marx. Su itinerario y su opción por el liberalismo no fueron fruto del estudio de 
las obras de Montesquieu, Constant o de Tocqueville, sino de El Capital.

Nuestro objetivo en este texto no es describir el recorrido de Aron desde Marx y contra él, tarea que llevó a cabo el propio francés (Aron 2001, 2010a), ni explicar las relaciones entre liberalismo y marxismo, sino mostrar los modos en que Aron leyó e interpretó a Marx y a los marxismos. Vamos a sostener que Aron lee a Marx con cautela y fascinación, y que explora críticamente los argumentos marxianos pero que, al mismo tiempo, no puede evitar rendirles homenaje. El Marx-profeta, blanco de sus críticas, es también el fiscal de las injusticias al que reconoce mérito porque es a través de él (con él y en su contra) que se despliega la dialéctica de las libertades (Aron, 1985b, 2014a). Pero si Marx es para Aron un gigante del pensamiento, no sucede lo mismo con los izquierdistas franceses que se identificaban como marxistas, a los que les dedica críticas agudas y ácidas (Aron, 1967, 1969). Con Marx, Aron es comprensivo y parsimonioso; con los izquierdistas se torna impaciente y acre. Sus distintas posiciones podrían entenderse a partir de los objetivos que Aron perseguía en cada caso (entender a Marx de un lado y combatir al izquierdismo del otro) o a que empleaba distintas lógicas discursivas (los tratados teóricos y las clases magistrales frente a los ensayos polémicos y las diatribas de ocasión). Sin quitar importancia a estas explicaciones, aquí trataremos de mostrar que las críticas de Aron tienen una base intelectual antes que exclusivamente política. Desde su perspectiva, las indagaciones de Jean-Paul Sartre, Maurice Merleau-Ponty, Louis Althusser y Emmanuel Mounier fallaban por distintos motivos, pero centralmente por uno: no comprendían el marxismo de Marx ${ }^{2}$. Desde esa perspectiva, nuestra contribución se divide en dos partes. En la primera presentamos la lectura aroniana de Marx basándonos en El marxismo de Marx, mientras que en la segunda abordamos las críticas de Aron a los marxistas franceses, haciendo eje en El opio de los intelectuales. Buscamos marcar cómo la lectura de Aron sobre Marx se vincula directamente con su mirada sobre el izquierdismo francés (que sobrepasa al marxismo) y estructura el eje de sus críticas.

\section{El discípulo inesperado: Aron lector de MarX}

Aron llegó al marxismo a través de los libros. No se trataba de lecturas incluidas en la currícula de su educación formal, que consideraba deficiente por no incluir a pensadores poskantianos (Aron 2001, p. 32), sino a acercamientos personales, influido por pautas epocales y por los acontecimientos europeos que se discutían en su juventud. Aron recuerda haber leído unos pocos textos de Marx y Engels en la década de 1920, pero fue en 1930, cuando expuso una clase sobre materialismo dialéctico que se le había encomendado, que sintió que se acercaba a Marx. Tras el seminario, el profesor Célestin Bouglé (antiguo colaborador de Émile Durkheim y maestro de Claude Levi-Strauss) le reprochó su visión "edulcorada" del marxismo, según la cual el materialismo dialéctico no era determinista, ya que, recurriendo a Engels, Aron había sostenido que la economía solo determinaba "en última instancia". Aron se confesó a sí mismo ignorante del pensamiento socioeconómico de Marx y se enfocó en El Capital, labor que nunca abandonaría.

¿Qué buscaba ese Aron de veinticinco años en El Capital? Si las preguntas que le hacía al texto eran económicas (¿cuál era el origen de la crisis europea?) o filosóficas (¿la filosofía de la historia libera al hombre de la carga de elegir?), lo que lo incitaba era la discusión política: ¿la vía revolucionaria al socialismo era inevitable?, ¿el comunismo debía adoptar necesariamente el rostro que mostraba en la URSS?, ¿era ineluctable la destrucción de esa sociedad burguesa en la que se había criado? (Aron, 2010a, pp. 85-86). Aron no halló en El Capital las respuestas que buscaba sino que lo que encontró fue, por un lado, un cúmulo de argumentos económicos que no terminaba de comprender y, por el otro, una cierta desazón ante la confirmación de que -desde su punto de vista- la obra de Marx era más determinista de lo que a él le hubiese gustado. Aron se desilusiona y se entusiasma a la vez: 
...comencé mi carrera intelectual con una reflexión sobre el marxismo; quise someter la crítica de mis opiniones o convicciones, evidentemente de “izquierda", que yo sentía en mí como inocentes, dictadas por el medio, sin otro fundamento que las preferencias espontáneas y las antipatías no probadas. Esta crítica comprendía (...) una confrontación con las perspectivas abiertas por el marxismo de Marx y la evolución de las sociedades modernas; [y] una toma de conciencian de las relaciones entre la historia y el historiador, entre la sociedad y quien la interpreta, entre la historicidad de las instituciones y la de las personas. En este sentido (...) yo no he separado nunca la filosofía de la política, el pensamiento del compromiso (...) (Aron, 1969, p. 9).

Leer El Capital transforma a Aron. En primer lugar, pasa a rechazar al comunismo de modo consciente y reflexivo; sus simpatías hacia la izquierda se apagan y sus prejuicios contra el comunismo se confirman. Ya no es solo un antifascista sino también un anticomunista. Pero, aunque se aleja de la izquierda, toma dimensión de la estatura colosal del pensamiento marxiano y siente el deber de esforzarse por comprender los meandros de una reflexión que lo fascina. ¿Cómo puede Marx combinar a Hegel y Ricardo? Aron no podía contestar aún este interrogante $y$, como parte de un plan de desarrollo intelectual orientado a la filosofía social, se dedica a complementar su formación filosófica con conocimientos de sociología y economía para retomar $E l$ Capital. Aron se convierte en un inesperado discípulo de Marx; no porque coincida con lo que éste dice, sino por estar en desacuerdo con él:

...para cada uno de nosotros, el hombre más importante es aquel con el que nos batimos (...) Las personas con las que se tienen más cosas en común no son necesariamente las que contribuyen a formar un pensamiento (...) Si quiere saber qué pensadores influyeron en mí, evidentemente el que ocupa el primer lugar es Marx. Hace treinta y cinco años que discuto con él. Es verdad que nunca fui marxista, pero también lo es que comencé mis investigaciones sobre filosofía social leyendo $E l$ Capital. Durante mucho tiempo traté de convencerme de que Marx tenía razón (...) No lo conseguí. Por lo tanto no me hice marxista. Aclarado esto debo reconocer que no hay ningún otro autor al que haya leído tanto o que haya influido tanto en la formación de mi pensamiento y del que haya hablado mal con tanta constancia. Digo esto simplemente para ilustrar una proposición trivial pero a menudo olvidada por los historiadores del pensamiento: la influencia no se mide por el grado de similitud sino por la importancia que un pensador tiene para otro (Aron, 2010b, pp. 296-297).

Si Aron va a construir su propia perspectiva dentro de la tradición liberal y a comprometerse en su combate contra el comunismo, lo hará esforzándose por adentrarse en la obra de Marx. No vamos aquí a sumergirnos en las discusiones acerca del modo en que Marx puede haber influido sobre la forma del liberalismo de Aron, tarea que requeriría un largo recorrido por otros textos ${ }^{3}$. Nos interesa, sí, resaltar que leer a Marx fue un parteaguas en el desarrollo intelectual de Aron. En primer lugar, muchos de los temas a los que el parisino va a dedicarse son tópicos marxianos, como la sociedad industrial, la economía política, la idea de progreso y la filosofía de la historia (Mahoney, 2003, p. 417). En segundo lugar, siguiendo a Marx, Aron se convertirá en un crítico de las sociedades contemporáneas, aunque en lugar de buscar una solución radical a los problemas ensaya respuestas parciales y mesuradas (Aron, 2010b, pp. 627 y ss.). Aron retiene de Marx la crítica, pero rechaza su visión de un mundo reconciliado, dejando a la justicia social apenas como un ideal regulativo que, al modo kantiano, ayuda a las sociedades en su movimiento asintótico hacia un futuro del que los hombres continúan siendo plenamente responsables (Mesure, 2015, p. 227).

Comprender "el marxismo de Marx" se tornó para Aron una herramienta para criticar tanto a los "socialismos reales" como a los intelectuales autotitulados marxistas. Contra los primeros sostuvo que, aunque carece de sentido discutir "qué es lo que diría Marx sobre...", sí puede afirmarse que el mundo soviético no es el que él había soñado (Aron, 2001, p. 424; 2010b, pp. 651-655). Contra los segundos, Aron estimaba que, aunque su lectura era solo una de las posibles, estaba más calificada que la de los filósofos que se acercaban a Marx sin estudiar ni las ideas, ni las prácticas, ni los mecanismos económicos y sociológicos propios del capitalismo (Aron, 1969, pp. 9 y ss.). 


\section{El marxismo de Marx}

Aron nunca escribió un libro sobre Marx. En sus memorias lamenta el hecho y advierte que su intención hubiera sido un texto que lograse "decantar lo esencial de las especulaciones filosóficas del joven Marx, comprender los grandes lineamientos de la economía tal como la presenta en la Crítica, los Grundrisse y El Capital, extraer de esas dos partes los diversos Marx posibles y las características del revolucionarioprofeta" (Aron, 2010a, pp. 976-977). El marxismo de Marx, editado por Jean-Claude Casanova y Christian Bachelier en 2002, se articuló a partir de notas manuscritas y desgrabaciones de clases de Aron. Como comentan los editores, el volumen se preparó para cumplir con su deseo de dar a conocer su lectura sobre Marx. Contra lo que había sostenido el filósofo, Casanova y Bachelier no eligieron basarse en el curso del Colegio de Francia de 1976-1977, sino en uno anterior, el de La Sorbona en 1962-1963. Esta opción se basó en que el curso de La Sorbona Aron trató con más detalle la obra de Marx, mientras que el del Colegio dio más espacio a la posteridad. Además, el de 1962-1963 era un curso de agregación para licenciados en filosofía, más denso y menos ceremonioso que el de 1976-1977.

El marxismo de Marx es erudito pero didáctico. A diferencia de otros críticos de Marx, Aron no busca demolerlo, sino comprenderlo, y por eso lo muestra bajo la mejor luz, destacando sus aciertos y exponiendo posibles explicaciones a sus falencias. Cuando señala desacuerdos, los expone de modo cristalino, mostrando de qué modo podrían rebatirse sus propios argumentos. Interesa destacar aquí dos cuestiones. Primero, que Aron muestra una interpretación de Marx que es eminentemente filosófica sin que esto implique ocuparse apenas de las obras del joven Marx; señala, por el contrario, que hay que considerar la obra completa para desentrañar una filosofía en movimiento. En segundo lugar, al francés le importa abonar a una línea de lectura que prioriza el entendimiento del mismo Marx sobre su propia obra:

...un autor puede ser leído de dos maneras (...) Una lectura se puede hacer desde el punto de vista de lo que ese autor consideraba esencial -es la lectura que intento hacer aquí-, tratando de sugerir (...) lo que Marx, en la época en que vivía y pensaba, consideraba esencial. Otro método de interrogación (...) consiste en interrogar a un autor del pasado centrándose en lo que en la actualidad consideramos esencial (Aron, 2010b, p. 370).

Así, "el marxismo de Marx" es el modo en que Marx entendía su propia obra y por eso es necesario un recorrido que dé cuenta de cómo el mismo Marx “llegó a ser marxista”. En este sentido, Aron propone una lectura según la cual lo que define al alemán como pensador es su transición de la filosofía hegeliana a una concepción de la historia como realización de la filosofía.

Si fuera posible resumir en unas pocas frases la empresa (...), esas frases serían las siguientes: Marx parte de la filosofía hegeliana, que es para él la culminación de la filosofía clásica, y considera que de ahí en más la verdadera filosofía no puede ser sino el pensamiento o la interpretación del mundo a partir de la economía, con miras a realizar (...) la filosofía (...) es indudable que [aquí] reside el sentido de la aventura intelectual de Marx, por lo menos como Marx y no como fundador de la Unión Soviética -esto último es un accidente histórico (...)- (Aron, 2010b, p. 23).

La lectura aroniana es distinta a la del revisionismo que busca rescatar al Marx hegeliano para darle un estatus superior al Marx economista y a las visiones economicistas que reducen El Capital a un estudio sobre el capitalismo. Busca mostrar que las obras de madurez de Marx son filosóficas y que, a la vez, representan el nivel más elevado de un periplo que comienza con una crítica de la filosofía hegeliana, sigue con un estudio crítico de la economía que permite reflexionar sobre el capitalismo y continúa con la realización de la filosofía en la historia a través de la acción revolucionaria. El Marx de Aron no es "solamente" un filósofo, ni un economista, ni un sociólogo, ni un profeta de la revolución; es todo eso junto, porque "la esencia del marxismo consiste en no establecer diferencias entre la sociología, la interpretación de la historia global y la voluntad de acción revolucionaria" (Aron, 2010b, p. 304). 


\section{El joven Marx}

Aron comienza su recorrido en 1848, con el Manifiesto Comunista y la Contribución a la Crítica de la Economía Política. En estas obras, dice Aron, ya vemos expresadas las ideas y los temas centrales de Marx: la concepción de crítica, la relevancia de la estructura social, el lugar de las relaciones de producción, la contradicción como motor de la historia, la lucha de clases, las revoluciones como expresión de la necesidad histórica, la relación entre la realidad social y la conciencia de esa realidad, los modos de producción históricos, y el lugar del comunismo en la historia. Luego, retrocede para explicar de qué modo Marx llegó a estas ideas y distingue tres períodos. En el primero, de 1818 a 1843, Marx es un joven hegeliano que comienza un proceso de ruptura con sus colegas, porque entiende necesario pasar de la crítica de las formas a una de las esencias, de una crítica de la religión a una crítica del derecho y del sistema social. El segundo período (1843-1845) está marcado por los Manuscritos Económico-Filosófiçomo intento de criticar conjuntamente economía, política y filosofía. El tercero (1845-1848) comienza con el materialismo histórico (La ideología Alemana y las Tesis sobre Feuerbach) y finaliza con la versión definitiva del Manifiesto (Aron, 2010b, pp. 35-54).

El estudio de los textos de juventud de Marx es rico y metódico. Aron se detiene a explicar una serie de pasajes enmarcados en un sentido biobibliográfico y colocados en el contexto de los debates políticos y filosóficos de la época, recurriendo en ocasiones a los argumentos de las interpretaciones modernas. Así, traza un mapa del itinerario intelectual de Marx que gira sobre el concepto de crítica: de la crítica de la religión a la del derecho y de allí a la de la economía. Esta concepción permite entender el punto esencialmente filosófico del marxismo: la relación entre un devenir necesario y las acciones de los hombres, "entre la teoría y la práctica, entre la necesidad histórica y la acción humana, entre la necesidad a secas y la libertad, entre la realidad y el pensamiento" (Aron, 2010b, p. 64).

Aron tiene un método compuesto por tres reglas. Primera: no puede considerarse al joven Marx como radicalmente opuesto al Marx maduro. Segunda: el pensamiento de Marx antes de 1848 no estaba firmemente establecido. Tercera: lo que no figura en los textos de un período determinado no estaba necesariamente ausente del pensamiento de Marx (especialmente en tanto no disponemos de los textos completos). Estas tres reglas permiten entender el recorrido intelectual de Marx y evitar la trampa de oponer un Marx a otro o hacer que ambos se corrijan entre sí (Aron, 2010b, pp. 60-64). Aron muestra no solo una lectura plausible de las obras juveniles de Marx, sino que refuerza su perspectiva exhibiendo las diferencias con las interpretaciones que postulan la primacía del Marx joven o corrigen El Capital recurriendo a ideas que el autor rechazó taxativamente en su madurez ${ }^{4}$. En el tratamiento del concepto de alienación, la diferencia de Aron con otras interpretaciones queda más clara. Con base en un razonamiento que debe más a la etimología que a la filosofía, sostiene que de las tres formas de alienación que Marx identifica en su juventud (la alienación del productor de su producto; la alienación del hombre de su esencia humana y la alienación de los hombres entre sí), solo la primera y la última sobreviven cuando Marx abandona la terminología hegeliana y combina su crítica del pensamiento con una crítica del mundo histórico (Aron, 2010b, pp. 167-191) 5 .

El capítulo que cierra la primera parte del libro es fundamental para la argumentación de Aron. Allí analiza la visión sobre la pauperización y la opresión de Miseria de la Filosofía para mostrar que Marx ya ha desarrollado in nuce su concepción de revolución como necesidad histórica. Esto lleva a Aron a una conclusión sorprendente: que Marx no era hegeliano. No se trata de desacreditar las lecturas de Éric Weil (1996), Alexandre Kojève (1969) o Giörgy Lukács (1970), sino de mostrar que, aunque Marx fuese un lector de Hegel y considerase la obra hegeliana como la culminación de la filosofía de su tiempo y aunque recurriera de modo habitual (incluso en su madurez) a la lógica, "nunca fue un discípulo de Hegel”, sino que más bien se dedicó a combatirlo (en el mismo sentido que Aron, lector de Marx, nunca fue marxista). Por eso, la interpretación del mundo que ofrece Marx, a través de “totalidades históricas” que se definen por "un estado de las fuerzas y las relaciones de producción” no tiene, según Aron (2010b, pp. 292-302), nada de hegeliano. 
Aron también se opone a la línea de interpretación de Georges Gurvitch (1961, 1971), que había sostenido que la dialéctica marxiana no guarda relación con la filosofía de Hegel, pero que sí tenía paralelismos con la obra de Henri de Saint-Simon. En primer lugar, dice Aron, que Marx no fuera hegeliano no implica que su obra no tuviera una relación auténtica con la de Hegel (en tanto Marx construye las bases del marxismo contra Hegel). Segundo, Gurvitch "trata de establecer lo que Marx hubiera dicho de haber sido un sociólogo al estilo de los sociólogos actuales (...). Yo trato de establecer lo que Marx quería y [él] lo que se puede conservar de Marx después de separar lo que (...) no le agrada”. Tercero, aun cuando la visión de Marx haya sido influida por Saint-Simon (punto que Aron discute), no sería correcto decir que Marx fue un sansimoniano: "nunca, en ningún texto, discutió Marx con Saint-Simon”. En este sentido, no alcanza con mostrar paralelismos entre el socialismo sansimoniano y la obra de Marx, ya que así como pueden hallarse similitudes también pueden encontrarse diferencias: por ejemplo, Marx suponía que las contradicciones entre opresores y oprimidos se agudizaban, mientras que los sansimonianos pensaban que se atenuaban. Pero, fundamentalmente, Marx se diferencia de los sansimonianos en una cuestión crucial: Marx era un ateo y fue ese ateísmo el que le permitió entender a la desalienación como la realización del hombre en este mundo; "si se toma en serio el marxismo como empresa filosófico-política, el ateísmo debe considerarse inseparable, intrínseco". En la visión de Aron el ateísmo permite combinar filosofía y política, crítica del pensamiento y de la realidad, "la unión de la filosofía y los proletarios" (Aron, 2010b, pp. 302-315). Marx no es un sansimoniano porque profesa una revolución necesaria que no aguarda la construcción impersonal de una nueva era, sino que urge a que los proletarios la construyan por sí mismos.

\section{Marx el marxista}

La segunda parte de El marxismo de Marx (igual que los anexos), tiene un enfoque distinto al de la primera sección. Ya establecido el itinerario que lleva a Marx al marxismo, lo que resta es mostrar en qué consiste el marxismo de Marx y elucidar hasta qué punto ese marxismo está presente en los debates tanto de los líderes políticos cuanto de los especialistas posteriores.

Para explorar al pensamiento ya asentado de Marx, Aron acude a El Capital (y de modo ocasional a los Grundrisse). El análisis no es original, pero sí sistemático. Aron (2010b, pp. 329-341) resalta la importancia de la interpretación de la economía ricardiana que hace Marx. Muestra el modo en que el fetichismo de la mercancía se relaciona con las discusiones de la economía clásica y la concepción crítica que Marx venía desarrollando en sus combates con Hegel (2010b, pp. 341-349) y en qué sentido el capitalismo es un sistema revolucionario que se reproduce a expensas de los trabajadores (2010b, pp. 356-363). A continuación, Aron (2010b, pp. 367-396, 411-420 y 707-714) se detiene en el concepto de plusvalor en el que confluyen la división del trabajo, el maquinismo, la cooperación, la manufactura y el ejército de reserva que son, en esencia, procedimientos para aumentar el plusvalor relativo. Así, el plusvalor es el secreto de la acumulación capitalista, el origen de su potencia transformadora y de la misma alienación.

Luego, el parisino estudia la tendencia a la baja de la tasa de ganancias, lo que le permite indagar sobre nociones económicas (capital, renta, interés), sociales (clases, intereses, asociaciones) y sobre el concepto de necesidad. Le interesa preguntar no solamente sobre el carácter antagónico, contradictorio y entrópico del capitalismo, sino también acerca de su posible final ineluctable en manos de una masa pauperizada. Aron discute por qué no resulta posible para los economistas actuales calcular el decrecimiento de la tasa de ganancias (y de paso clarifica por qué la economía contemporánea que se ocupa de los fenómenos no discute con un marxismo preocupado por la esencia detrás de lo aparente). Contra Schumpeter (1996, que lee a Marx como un economista positivista) y Bigo (1966, que lo interpreta como un filósofo alejado de lo empírico), Aron insiste en que El Capital es un libro de ciencia económica distinto a otros libros económicos porque con él Marx pensaba estar realizando un análisis de la sociedad y al mismo tiempo una crítica de esa misma sociedad, así como de los capitalistas y economistas burgueses incapaces de comprender las contradicciones 
que desembocarían en la necesidad de revolución. Del mismo modo que el joven Marx discutía con los hegelianos mostrando que la ideología era una conciencia falsa de una falsa realidad, el Marx maduro quiere mostrar que los capitalistas y los economistas tienen una percepción equívoca de una realidad contradictoria. Pero para Aron se trata de una empresa fallida, principalmente porque no puede demostrar la tendencia decreciente de la tasa de ganancias y, entonces, el final inevitable del capitalismo.

Lo que reprocho a casi todos los intérpretes actuales de Marx, es que no advierten que en el pensamiento de éste había una unidad orgánica entre el razonamiento económico y el significado filosófico-histórico de ese razonamiento (...) la condición de esta síntesis es la noción de crítica de la economía política, es decir de crítica simultánea de la realidad y de nuestra toma de conciencia de esa realidad. Siendo así, ¿por qué son tan pocos los estudiosos que aceptan interpretar a Marx en El Capital como Marx se pensaba a sí mismo? (...) La razón (...) es que cuesta mucho admitir que la tarea que intentó llevar a cabo Marx (...) no tuvo éxito (Aron, 2010b, p. 441).

Los capítulos XIV a XVI explicitan las relaciones entre la crítica de la economía política de Marx, que para Aron (2010b, pp. 469-472) había fracasado, con la filosofía de la historia y la profecía revolucionaria. Aquí, cuestiones que suelen ser tratadas puntillosamente por los analistas de Marx, como la lucha de clases, la distinción entre clases y fracciones, las formaciones económico-sociales, el campesinado, la democracia burguesa y la dictadura del proletariado, se abordan sumariamente. Lo que interesa a Aron no es tanto discutir detalles, sino mostrar cómo se engarzan economía, filosofía e historia. Una forma de abordar el problema es la discusión del papel de la violencia y la necesidad ${ }^{6}$. Al considerar el paso de un modo de producción a otro, Aron (2010b, p. 490) muestra que Marx adjudica un rol fundamental al uso de la fuerza, como en el proceso de acumulación originaria. El problema es que una vez que "se introducen la guerra, el Estado y las conquistas para explicar el nacimiento y la desaparición de regímenes económicos, se complica (...) la interpretación clásica de la historia que se atribuye a Marx". Si se requiere de la guerra y los Estados para cambiar de modo de producción, resultaría que el fin del capitalismo no se desprende de leyes inmanentes ${ }^{7}$.

Para explicar el final del capitalismo Marx recurre a una doble dialéctica. Por un lado, la dialéctica económica de la contradicción entre las fuerzas y las relaciones de producción. Por el otro, la de la lucha de clases que se expone en textos sociológicos, como El 18 Brumario de Luis Bonaparte o La lucha de clases en Francia. Las dos dialécticas se combinan cuando se pasa de una teoría abstracta de las clases sociales a una teoría concreta, cuando el proletariado toma conciencia de su rol y se convierte en clase revolucionaria. Pero en este punto, Marx ya no está ni en el terreno de la economía ni en el de la sociología, sino en el de la filosofía de la historia. En efecto, el marxismo de Marx es una filosofía de la historia que se enuncia "en relación con el desarrollo de las fuerzas productivas, en relación con las contradicciones entre las relaciones de producción, o en relación con la lucha de clases". Estas relaciones no son independientes y deben ser entendidas en su relación dialéctica, lo que dificulta una fórmula única del devenir histórico. Sin ese esquema histórico en el cual las tres relaciones se desarrollen de forma paralela, "se hace cada vez más difícil pasar de la teoría abstracta del devenir capitalista (...) a la historia real del devenir del mundo actual” (Aron, 2010b, pp. 608-610). Así:

...se necesita de la acción para que la teoría marxista de las clases sea verdadera, porque es a la vez un análisis y una voluntad. Es un análisis en el sentido de que muestra la situación del proletariado en la sociedad capitalista, y es una voluntad en el sentido en que tiende a enseñar al proletariado explotado las condiciones de su liberación (...) Para que esta teoría culmine en una acción que la confirme deben cumplirse dos condiciones. La primera es que el devenir del capitalismo se parezca lo bastante al que se representaba Marx (...) La segunda es que el proletariado (...) reaccione como debería reaccionar... (Aron, 2010b, pp. 501-502).

Aron señala con ironía que, si la crisis capitalista no adviene, el proletariado aún puede actuar de modo revolucionario (como propuso la III Internacional), o bien, si no quiere hacer la revolución que la teoría exige, puede aguardar a que las contradicciones se agudicen (como postuló la II Internacional). Los herederos de Marx parecen condenados a bascular entre la tesis y la antítesis, sin llegar a la síntesis. El origen de esta fatalidad podría encontrarse en tres razones distintas. En primer lugar, la ausencia de un tratamiento exhaustivo de la política en el pensamiento marxiano: si Marx habla de política, lo hace a través de "una teoría de la negación 
de lo político como dominio específico de la realidad humana o histórica" (Aron, 2010b, p. 610). En segundo lugar, y debido a que Marx rechazó dar precisiones sobre los rasgos del comunismo, hay ambigüedades con respecto a su idea de libertad, pues no queda claro si la negación de la alienación se produce en el ámbito de lo público -en el trabajo que dignifica-, o en el mundo privado -en el tiempo del ocio- (Aron, 2010b, pp. 614-615). Finalmente, y más allá de los vaticinios catastrofistas sobre la pauperización y las profecías revolucionarias, el mundo contemporáneo muestra un desarrollo desigual de las fuerzas productivas, una distancia entre las relaciones de producción en los países desarrollados y los no desarrollados. Esas diferencias no pueden explicarse apenas por el despliegue de la lucha de clases (en el sentido de derechos arrancados a la burguesía), sino que son resultado de muchos y distintos factores que incluyen cuestiones como la libre asociación y la democracia política (Aron, 2010b, p. 653).

El libro de Aron se cierra recordando que su interpretación no es la única posible, pero que sí es una lectura razonable de lo que Marx quiso decir y hacer. Pero también muestra que hay otras interpretaciones que no pueden sino calificarse de espurias: "los planificadores soviéticos aunque continúan citando a Marx, difícilmente podrían ser considerados sus herederos" (Aron, 2010b, p. 655). Como veremos a continuación, lo que Aron opinaba de los intelectuales franceses sigue esta misma línea.

\section{Debates EN TIEMPos DE GUERRA Fría}

La interpretación de Aron en El marxismo de Marx no difiere de la que ofrece en textos anteriores (Aron, 1939) o posteriores (Aron, 2010a), lo cual resulta central para la pauta que proponemos: mostrar que cuando Aron critica a los izquierdistas franceses no está polemizando por mor de su liberalismo o considerando las posiciones de la guerra fría, sino discutiendo la pertinencia de la postura "no comunista" desde un anticomunismo basado en su lectura de Marx.

Tras la Segunda Guerra, Francia era un terreno de debates que iban desde la "depuración” que permitió juzgar a los colaboracionistas de Vichy hasta las discusiones sobre el rol del Estado francés en el orden internacional y las tradiciones de pensamiento. En particular, las polémicas sobre el orden político desbordaron la academia e incluso el espacio intelectual (Lottman, 1994; Sirinelli y Ory, 2007; Winock, 2010). Pero, como muestran distintos estudios (Dosse, 2007; Charle, 2009; Traverso, 2001), la figura del intelectual francés - nacida con el "caso Dreyfus" - se construye y reposiciona en debates de gran calibre. En tal contexto, el marxismo -ideario al que adhirió una gran parte de la intelectualidad francesa- se torna objeto de disputa, lo que hace comprensible el éxito de la publicación de Elopio de los intelectuales en 1955. Gracias a ello, además, este libro fue el único al que dedicó un capítulo exclusivo en las Memorias.

Para Aron, el marxismo de los intelectuales no es el de Marx, sino una versión deformada por el dogma soviético, la frivolidad y una profunda incomprensión de la obra marxiana y de la realidad política de la segunda posguerra. Pero si el objetivo general del libro era una suerte de denuncia a la cultura izquierdista, parte de su repercusión se debió a su tono ácido. Por medio de su crítica a Sartre y Merleau-Ponty, Aron enjuicia a un sector de la intelectualidad francesa -al que acusa de justificar la represión estalinista, desconocer las complejidades del pensamiento de Marx y promover visiones banales del socialismo y las democracias occidentales-, pero también a una parte de la opinión pública que adhería a ese izquierdismo que el autor entendía opiáceo.

\section{Izquierda y derecha}

Aron no se consideraba a sí mismo alguien de derecha. Aunque participó del Coloquio Walter Lippman -que en 1938 dio origen a la red de intelectuales neoliberales que formarían la Sociedad Mont Pèlerin (Reinhoudt \& Audier, 2018; Denord, 2009)-, ya en 1950 se oponía abiertamente a lo que considera un liberalismo economicista y estéril (Aron, 1985c). Contra ese liberalismo, Aron sostenía una posición plural 
y ecléctica. En el prefacio de El opio de los intelectuales se ve a sí mismo como un keynesiano inclinado hacia el liberalismo, favorable a la independencia de las colonias francesas y convencido de la relevancia de la Organización del Tratado del Atlántico Norte. ¿Debería ser clasificado como alguien de izquierda o de derecha? La respuesta a esta pregunta depende de lo que se tuviere en cuenta, si su perspectiva económica, su mirada sobre la descolonización o su postura en el conflicto Este-Oeste (Aron, 1967, pp. 9-12).

De acuerdo con Aron, izquierda y derecha no representan dos bloques "separados por un centro sin cesar atacado", sino que son una díada que puede ser comprendida acudiendo a tres pautas: la antropológica (dos tipos de hombre), la ideológica (dos concepciones de mundo) y la sociohistórica (dos espacios cuya lucha marca un combate de dos siglos). Cada una de estas construcciones depende del contexto y de normas propias de lo que hoy denominaríamos historia intelectual (al menos en los términos de François Dosse, 2007). Sin embargo, en algunas situaciones, como la de Francia en el siglo XX, estas construcciones relacionales se presentan como si estuviesen enredadas. Por eso Aron sostiene que "el caos ideológico en la Francia actual se origina en la confusión entre los distintos sentidos en los que resulta susceptible de ser considerada la oposición entre derecha-izquierda. Esta misma confusión es ampliamente imputable a los hechos", es decir, a la historia política francesa que ha legado un presente en el que aún parece tener sentido discutir sobre el Antiguo Régimen y la Revolución. "En ninguna parte conserva tanto prestigio como en Francia la oposición entre la derecha y la izquierda, en ninguna parte es más equívoca" (Aron, 1967, pp. 38-40). De allí, Aron concluye que Francia es la patria del antagonismo derecha-izquierda. Pero como se trata de un antagonismo imbricado, allí se produce un triunfo terminológico de la izquierda, que logra encaramarse en una suerte de pedestal moral e intelectual. Desde esa posición, la izquierda observa con desdén no solo a los partidos conservadores sino también a los moderados, a los que impone hablar con su propia gramática. Así, el discurso político galo está imbuido de izquierdismo, pero la victoria izquierdista en el reino del discurso se produce al precio de perder claridad y densidad conceptual. El morbo gallico consistiría, así, en la hegemonía izquierdista en el mundo de las palabras. El remedio podía encontrarse al otro lado del Canal de la Mancha: en El opio Gran Bretaña es el ejemplo a imitar, el lugar donde las palabras se emplean de modo menos equívoco y la política puede ser objeto de una discusión profunda.

En 1950, la derecha aparece como el "partido de la tradición y de los privilegios, contra la izquierda" que es "el partido del porvenir y la inteligencia". Aron señala que "esta interpretación no es falsa [pero] representa exactamente la mitad de la verdad", por su dicotomía sencilla. Los bloques solo adquieren forma monolítica en determinadas circunstancias (como en el affaire Dreyfus), y aun en esos casos se trata de una mirada retrospectiva que busca camuflar las "querellas implacables" al interior de posiciones ineptas para formar alianzas competentes: "la incapacidad que alternativamente muestran las derechas o las izquierdas para gobernar juntas (...) caracteriza la historia política de Francia desde 1789”, sentencia Aron (1967, pp. 17-21). La izquierda, concluye, es un mito en sí misma.

Pero si las culpas son compartidas por derecha e izquierda, a esta última le cabe mayor responsabilidad, porque domina el campo de las ideas y mantiene un cisma entre clase obrera y burguesía que se revela en explosiones periódicas y porque está dejando perecer sus propios principios. La libertad contra las arbitrariedades, la sustitución del orden espontáneo de la tradición por el de la razón y la igualdad contra los privilegios de nacimiento o de fortuna dejan paso a una perspectiva sectaria, en la que solo cabe la compasión por quienes son afines. Los que desesperaron frente a la tibieza de la "depuración" son los que se indignan ante el caso Rosenberg empleando formas argumentativas inaceptables (Aron, 1967, pp. 19, 221- 222).

Luego, Aron pasa a ocuparse de los métodos de la izquierda. Así distingue a una izquierda moderada, la del laborismo británico, que se caracteriza por ofrecer un futuro factible en el cual los principios se mantienen de un modo equilibrado aunque realista, de otra desmesurada, con epicentro en la Unión Soviética, en la cual una clase dirigente reemplaza a la libertad por la servidumbre en nombre de la razón y la igualdad (Aron, 1967, pp. 44, 85-86). El totalitarismo soviético no es, según Aron, una desviación inesperada, sino el fruto del mito 
revolucionario. En contra de la reforma prosaica (al estilo laborista), el revolucionario torna los principios en ideales y se lanza a una aventura poética y grandiosa, la de erradicar las injusticias (Aron, 1967, p. 50). El mito revolucionario tampoco es casual, se deriva de la escatología marxista que demanda la revolución a manos de otro mito: el del proletariado como "salvador colectivo" de la humanidad y como agente de la Historia (Aron, 1967, pp. 75 y ss.). Al leer a Sartre, Aron observa la conjunción del mito revolucionario y del proletariado:

\begin{abstract}
El itinerario de Sartre hacia el paracomunismo parece dialéctico (...) La visión radiante de la sociedad sin clases sucede a la descripción de la sociedad viscosa, así como, en los novelistas del naturalismo, el optimismo político se combina de buen grado con la pintura de las bajezas humanas (...) La filosofía de los existencialistas es de inspiración moral. A Sartre lo [obsesiona] la preocupación por la autenticidad, la comunicación, la libertad. Toda situación que paraliza el ejercicio de la libertad es contraria al destino del hombre. [Pero] el radicalismo ético, combinado con la ignorancia de las estructuras sociales, lo predisponía al revolucionarismo verbal. El odio a la burguesía lo aleja de las reformas prosaicas. El proletariado no debe pactar con los "puercos" (...) Así, un filósofo, que excluye toda totalidad, vuelve a introducir la vocación de la clase obrera, sin adquirir conciencia de una contradicción menos superada que disimulada (Aron, 1967, pp. 86-87).
\end{abstract}

De acuerdo con la teoría marxista la revolución es ineluctable y es necesario que sea el proletariado, que no tiene nada que perder excepto sus cadenas, el que la realice. Pero en el siglo XX, los trabajadores de los países desarrollados (el ejemplo es británico) ven que esta es una mistificación. Ellos saben que tienen cosas que perder: no solo los beneficios que han podido obtener con el crecimiento económico, también sus libertades (Aron, 1967, pp. 84 y 101). Por supuesto que no en todos los países la situación de los trabajadores ha mejorado, reconoce Aron, pero lo mismo puede decirse de las naciones comunistas que, además, han suprimido libertades:

Una rebelión del tipo soviético otorga el poder absoluto a la minoría que invoca al proletariado y transforma a muchos obreros o hijos de obreros en ingenieros o comisarios. El proletariado mismo, es decir, los millones de hombres que trabajan con sus manos en las fábricas, ¿son liberados? El nivel de vida no ha progresado súbitamente en las democracias populares de Europa Oriental; más bien ha disminuido (...) Allí donde existían sindicatos libres, sólo existen ahora organismos sometidos al Estado, cuya función es incitar al esfuerzo, no reivindicar. El riesgo de paro ha desaparecido, pero también han desaparecido la libre elección de oficio o lugar de trabajo, la elección de los dirigentes sindicales, de los gobernantes (Aron, 1967, p. 82).

En vista de esta "realidad", Aron (1967, p. 104) concluye que los tres mitos -izquierda, revolución y proletariado- fueron derrotados más por sus éxitos que por sus fracasos. Superadas las mistificaciones, las sociedades del siglo XX tienen la oportunidad de avanzar moderadamente equilibrando "planificación e iniciativa, retribuciones equitativas para todos e incentivo para el esfuerzo, poder de la burocracia y derechos de los individuos, centralización económica y salvaguardia de las libertades intelectuales”. Solo así será posible caminar hacia el ideal político que, desde Aristóteles, los hombres se han puesto como norte: la vida buena. Y ese no es un proyecto de derecha, porque "la única izquierda, siempre fiel a sí misma, es la que invoca no la libertad o la igualdad, sino la fraternidad, es decir, el amor" (Aron, 1967, p. 32).

Para Aron, desde que se produjo la crisis económica de 1930, la izquierda avanzó apelando a un marxismo poco doctrinario, combinando "en una síntesis confusa la propiedad pública de los instrumentos de producción, la hostilidad a las concentraciones de poder económico [y] la desconfianza respecto a los mecanismos del mercado". Así, estar a la izquierda puede ser tanto apoyar las nacionalizaciones y los controles como procurar la igualdad de ingresos, objetivos que se pueden alcanzar con diferentes dosis de continuidad y ruptura y distintos énfasis en el aspecto liberador o la faz organizadora del socialismo. Pero esta amplitud y diversidad que Aron parece celebrar es el mismo factor que hace posible que en el caso de Francia la izquierda se muestre de forma confusa, insistiendo algunas veces en su ruptura total con la burguesía y otras en la continuidad de la Gran Revolución (Aron, 1967, p. 19). Y es en buena medida porque la izquierda se presenta ambiguamente que sus políticas tienden a ser problemáticas. Así, las propuestas de la izquierda francesa buscan redistribuir el poder entre los privilegiados de la sociedad antes que cambiar la relación entre fuertes y débiles, ricos y pobres: "Las bonificaciones familiares financiadas con una tasa sobre los salarios (...) favorecen a los padres de familia o a los viejos a expensas de los jóvenes y de los solteros”. El problema no es 
la redistribución, sino que la misma se hace a expensas de los más productivos. Puede ser que a la izquierda le quepa preocuparse más por evitar los sufrimientos que por acelerar el progreso económico, pero, en ese caso, resultaría que los comunistas ortodoxos "no pertenecerían a la izquierda" (Aron, 1967, p. 31). Los instrumentos y las intenciones, en la izquierda, son puestos por encima de cualquier consideración, como en un embelesamiento:

Los hombres de izquierda cometen el error de reclamar, para ciertos mecanismos, un prestigio que, en justicia, pertenece sólo a las ideas: propiedad colectiva o método de ocupación plena deben ser juzgados por su eficacia, no por la inspiración moral de sus partidarios. Cometen el error de imaginar una continuidad ficticia, como si el porvenir siempre valiera más que el pasado, como si, teniendo siempre razón el partido del cambio contra los conservadores, pudiéramos considerar adquirida la herencia, y preocupamos exclusivamente por nuevas conquistas (Aron, 1967, pp. 31-32).

Contra el izquierdismo que oscila entre el romanticismo y el "despotismo anónimo", conservadurismo y liberalismo se alían. De acuerdo con Aron, mientras que los conservadores aportan el sostén de "los frenos del pasado" (la tradición, la herencia histórica, el devenir moderado) los liberales se oponen al Estado total y la falta de libertad y progreso. La posición de unos aparece dependiente de la de los otros (Aron, 1967, pp. 28 y ss.). En ese movimiento, Aron se entronca en la renovación liberal-conservadora de la segunda posguerra (Nash, 1987).

Lo que Aron quiere discutir desde el liberalismo conservador es la filosofía de la historia. Sostiene que la izquierda crea la ilusión de un "movimiento histórico, orientado hacia un fin feliz, [en el cual] las libertades reales, gracias al socialismo, se agregarían a las libertades formales, forjadas por la burguesía”. Pero la historia es dialéctica, no en el sentido de que los distintos regímenes sean contradictorios, sino porque en el interior de cada uno hay tensiones que no pueden ser resueltas por mera voluntad. Buscando igualdad, bien se puede resignar la libertad: "De Tocqueville había demostrado (...) a qué conduciría el impulso irresistible de la democracia si las instituciones representativas se dejaran llevar por la impaciencia de las masas; si el sentido de la libertad, originariamente aristocrático, llegara a debilitarse" (Aron, 1967, pp. 29-30).

\section{Los intelectuales izquierdistas y el comunismo}

Los comunizantes - los que, incluso sin adherir al partido, orientan sus simpatías hacia el mundo soviético (Aron, 1967, p. 9)- no se resignan al sendero prosaico de las reformas, que sería una forma segura de avanzar, y prefieren la redención por medio de la dimensión profética de un marxismo con contornos de religión atea ${ }^{8}$. Como toda religión que se precie, este marxismo tiene su línea ortodoxa (la del Partido) y diversas heterodoxias (las posiciones de los intelectuales) y sectas (los grupos minoritarios). En ese enfoque, los juicios estalinistas y los apercibimientos a quienes se apartan de la línea oficial aparecen como el momento de la inquisición que impide cualquier cuestionamiento a lo que ya no es teoría, sino dogma (Aron, 1967, p. 124).

Comunistas ortodoxos e intelectuales comunizantes siguen un mismo patrón. Cuando leen a Marx (si lo leen), lo hacen de manera poco marxista. No se inquietan ante la realidad concreta; permanecen en el reino de la abstracción y no revisan sus posturas. Si el proletariado no se erige en clase universal, si la revolución no llega a los capitalismos avanzados o si la liberación no sigue a la revolución, comunistas y comunizantes no preguntan (ni dejan que nadie pregunte) si no podría tratarse de un error filosófico haber encomendado a los obreros la misión redentora o indagar si es cierto que la toma del poder por un partido que se reserva el monopolio del Estado es el prefacio indispensable para la realización de la historia (Aron, 1967, pp. 123-124).

A la hora de las críticas puntuales, Aron abordó tres casos: la polémica entre Sartre y Albert Camus, el texto Humanismo y Terror de Merleau-Ponty y el grupo católico Esprit. A ellos, además de ligarlos a los errores de la izquierda, Aron los calificaba -con amarga ironía - como "intelectuales de buen corazón", que, lejos de conmoverse por los "excesos" de la "depuración", habían exigido mayor virulencia (Aron, 1967, pp. 222-223). En esa actitud veía los dislates de la izquierda: justificación de la represión de los disidentes rusos 
(en el caso de asunción de valores de izquierda en nombre de sectores populares, desligados de su realidad (el catolicismo progresista).

El debate entre Sartre y Camus acerca del caso soviético fue un pleito resonante y tuvo inmediato impacto internacional debido a que se trataba de dos de los más importantes autores del momento. Aron opina que el análisis de Camus era deficiente y poco original, pero también sostiene que su denuncia del régimen soviético no fue -ni podía ser- refutada con propiedad por Les Temps Modernes, la revista dirigida por Sartre. De esa polémica, el dato esencial era que el autor de El extranjero buscaba denunciar "la existencia de iniquidades" en ambos campos del mundo bipolar, sin pararse en ninguno de ellos, mientras que el creador de La náusea, aunque en teoría estaba situado en ese mismo lugar equidistante, solo se interesaba en criticar las injusticias en el mundo occidental (Aron, 1967, pp. 61 y ss.). Si bien reconoce la imperfección en la exposición de Camus, Aron indica que Sartre entra al debate valiéndose de artimañas. Así, ante la pregunta de Camus acerca del sentido y del fin de la historia en la concepción marxista, Sartre replica que Marx nunca habló del fin de la historia, sino del final la prehistoria (lo cual es cierto, pero no responde al planteo de Camus), y que la historia solo tiene el sentido que le asignan los hombres con sus acciones; pasa por alto la complejidad de elegir un sentido si somos incapaces de determinar los valores universales o comprender el conjunto (Aron, 1967, p. 63).

Para Aron el problema profundo de la posición sartreana, más allá de su mala fe al polemizar, estriba en el intento de Sartre de justificar su postura de limitarse a criticar al mundo capitalista (aun cuando su humanismo debería llevarlo a actuar como Camus) basándose en una lectura inadecuada del marxismo. "Sartre toma del marxismo, nos dice, entre el profetismo y el método, ciertas verdades (...) filosóficas (...) la crítica de la democracia formal, el análisis de la alienación y la afirmación de la urgencia en abatir el orden capitalista”. Lo que hace Sartre es tomar pasajes del joven Marx, olvidar que este revisó su postura sobre esos temas y extraer de allí una visión profética que, a diferencia de los análisis económicos, sociológicos e históricos sobre la concentración de las empresas y la pauperización de las masas, no puede ser desmentida por los hechos. Se trata de un profetismo sutil y abstracto, incapaz de responder a la pregunta camuseana sobre en qué sentido la toma del poder por un partido marca el fin de la prehistoria (Aron, 1967, p. 63).

A Merleau-Ponty Aron le dedica varios pasajes en distintos capítulos de El opio de los intelectuales y lo aborda con mucho mayor rigor que a su antiguo compañero de la École Normale ${ }^{9}$, mostrando el modo en que se conjugan lo que entiende como errores filosóficos con una posición política que lo indigna (Aron, 2010a, p. 401). Merleau-Ponty quiere probar que el marxismo no es apenas una hipótesis, sino que es el enunciado de las condiciones sin las cuales no habría humanidad en el sentido de una relación recíproca entre los hombres, ni racionalidad en la historia. Una idea "dogmática y a la vez ingenua", dice Aron, "que expresa la convicción de que el marxismo se confunde con la filosofía de la historia [y por eso] es definitivamente verdadero". Pero, en lugar de buscar las bases de esta verdad en las relaciones de producción, Merleau-Ponty basa su perspectiva "en dos ideas esenciales: debemos referirnos a las existencias vividas para apreciar los sistemas político-económicos [y] el reconocimiento mutuo es característico de la comunidad propiamente humana". Las dos ideas son aceptables pero equívocas, señala Aron. La primera implica que las relaciones interhumanas absorben la existencia de todos y, así, bajo la "capa de una crítica efectivamente válida [a las miradas estructurales], Merleau-Ponty introduce la negación de las trascendencias y de la vida interior”. Y aunque la segunda idea recuerda al joven Marx, aquí se trata de un reconocimiento impreciso, que no está ligado a una filosofía o concepción de la historia (Aron, 1967, pp. 119-120).

Marx no consagró su vida a razonar sobre temas filosóficos, sino a analizar la economía y la sociedad para discernir en ellas el camino de la Razón a través de la confusión de los acontecimientos. Una doctrina fenomenológica que describe las experiencias de cada uno e ignora si la procesión de las sociedades cumple el progreso de la humanidad debe dar un contenido a la noción de reconocimiento. A falta de lo cual, no permite juzgar el presente, ni decidir sobre el porvenir (...) Si se pretende eliminar radicalmente desigualdades y rivalidades, si la autoridad de unos no debe exigir más la resignación de los otros, entonces el Estado posrevolucionario exige una transfiguración de la condición social de todos. Así el joven Marx especulaba con el fin de la distinción entre el sujeto y el objeto, la existencia y la esencia, la naturaleza y el hombre. Pero esto sería 
justamente apartarse del pensamiento racionalista y limitarse a traducir a un vocabulario filosófico el sueño milenario o la espera religiosa del fin de los tiempos (Aron, 1967, pp. 120-121).

En otros términos, o bien se sigue el marxismo de Marx y con él una dialéctica racionalista, o bien al joven Marx, y con él a un ensueño redentor. Merleau-Ponty quiere tener a uno con el otro, confundiéndolos. Por otro lado, Merleau-Ponty condona la ideología soviética al suponer que la humanización de la sociedad no es la obra común de una humanidad que en su desarrollo busca (sin lograrlo, claro) suprimir la separación entre lo real y la idea, sino la obra (ya cumplida) de una clase, o del partido que representa a esa clase en el Estado. "Así vuelve a incurrirse en el error que Marx tuvo el mérito definitivo de denunciar: juzgar a las sociedades según su ideología y no según la suerte que reservan a los hombres" (Aron, 1967, p. 123). Para peor, el error filosófico se traduce en catástrofe en el plano político, porque desde la óptica “idealista” el marxismo es razón y redención inapelable y no puede aceptar desviaciones ni claudicaciones. Es en esa línea que debe entenderse, piensa Aron, su actitud frente a las purgas y juicios estalinistas, una actitud más penosa que la de los propios comunistas ortodoxos. El ortodoxo defiende unos procesos en cuya verdad no creía "ni Stalin", pero no ignoraba que los mismos eran fraguados y sabía perfectamente de la existencia de campos de concentración, aun cuando los llamase "campos de reeducación". Pero el idealista da un paso más: cegado por el dogma oficial supone que los juicios son ceremonias de palabras, y los campos, reformatorios. De modo similar, el ortodoxo no tiene certidumbre sobre el detalle de los acontecimientos, pero eso no lo lleva a dudar de las grandes líneas que enseña el partido. En tanto, el idealista sí duda, pero aún así decide confiar y ser indulgente, espera ser convencido. Finalmente, el ortodoxo tiende a ampliar lo más posible el objeto de su $\mathrm{fe}$, relacionando incidentes y accidentes con las líneas del partido que logran explicar y ordenar todo en un mundo carente de azar. El idealista admite la contingencia, pero cree que la historia terminará en el mismo lugar. Así, aunque el ortodoxo lleva la lógica del sistema al nivel del horror, es el idealista quien recrea los peores vicios en un lenguaje digerible para los que no son miembros del partido. Al final, para ambos, la historia es el tribunal supremo donde todo encaja en una construcción perfecta (Aron, 1967, pp. 123-126).

Para Aron, el error político de Merleau-Ponty no se agotaba en su condescendencia hacia el mundo soviético, también se extendía a su percepción negativa de las sociedades liberales, que, no por azar, eran las únicas en las que su análisis de los procesos estalinistas se podía publicar y discutir: “¿Por qué razona el filósofo como si la libertad, sin la cual sería condenado al silencio o a la obediencia, no tuviera precio alguno?”, se pregunta Aron (1967, p. 129). Este interrogante no era irónico; no pretendía cerrar la discusión, sino abrirla. Y aunque el debate no tuvo lugar, como recuerda Aron (2010a, p. 415), "Merleau-Ponty se cansó de esperar la armonía entre la historia real y la visión marxista (...) sin llegar a estar de acuerdo conmigo, se había acercado a mis posiciones [en Las aventuras de la dialéctica, publicado como el libro de Aron en 1955]"10.

Las discrepancias entre Aron y Merleau-Ponty no llevaron a una ruptura total de relaciones; pero otra fue la historia con Sartre. El punto de quiebre fue un debate radial que comenzó cuando el equipo de Les Temps Modernes comparó a Charles De Gaulle con Adolf Hitler, y siguió cuando dos gaullistas (el general Pierre de Bénouville y el abogado Henri Torrès) atacaron a Sartre de forma impiadosa sin que Aron, que oficiaba de moderador, interviniera (Cohen-Solal, 1990, pp. 388-394). De todos modos, Sartre (1973) recogió algunos de los señalamientos de Aron. En uno de los tomos de Situaciones criticó con dureza las posiciones conservadoras de la academia francesa (destacando el papel de Aron) pero también revisó sus posturas sobre el régimen soviético y el Partido Comunista, enfatizando su idea del intelectual como sujeto crítico incluso en sus contradicciones. Sin embargo, para entonces los estudiantes franceses ya habían popularizado la frase "Prefiero estar equivocado con Sartre que acertado con Aron", con lo cual la polémica ingresaba en otros carriles. Las invectivas estudiantiles reflejaban con precisión el tipo de postura izquierdista que Aron denunciaba en El opio de los intelectuales: apoyo irreflexivo, idealista y dogmático al comunismo y rechazo a la democracia moderada, plural y reformista que -desde su perspectiva- el mundo capitalista había aprendido a cobijar. 


\section{CODA}

En este trabajo intentamos plasmar cómo la lectura que Aron realizó de Marx fue clave no solo en la constitución de su itinerario intelectual, sino también en sus posturas en contra de la izquierda francesa de mediados del siglo XX, a la que fustigó por ser condescendiente con la Unión Soviética y extremadamente crítica con los países capitalistas. Los sealamientos de Aron a autores como Sartre y Merleau-Ponty lo posicionaron -quizá de modo irremediable- en el lugar de un guerrero frío y un antimarxista. Sin embargo, aquí procuramos matizar esa mirada reduccionista, mostrando que, independientemente del posicionamiento geopolítico de Aron y más allá de su perspectiva anticomunista -y en favor de un liberalismo con tendencias conservadoras-, una parte de su argumentación se basa en su interpretación del "marxismo de Marx", donde se forja la base de su amonestación a la intelectualidad de izquierda.

Aunque su lectura de Marx es controversial, sobre todo en lo que se refiere a su perspectiva sobre la alienación y la tendencia decreciente de la tasa de ganancias, su interpretación es razonable y abierta al debate, como lo son sus argumentadas críticas a los intelectuales de izquierda, de quienes Aron marcó repetidas veces esperar mejores polémicas y no simples ataques. Su modo de leer a Marx y basar sus ideas en los trabajos del alemán otorga a Aron un cariz especial entre la intelectualidad francesa de mediados del siglo pasado y dentro de la misma renovación liberal-conservadora internacional: un autor que se forma desde y contra Marx, que discute de modo analítico con el legado del autor de Tréveris y de manera desembozada contra sus seguidores galos. Las polémicas en torno al suceso de El opio de los intelectuales configuraron el modo en que Aron fue interpretado posteriormente, lo que redundó en una lectura reduccionista tanto de su figura como de su relación con el universo marxista.

Tras lo enfocado, este artículo deja abiertos dos caminos para transitar. Por un lado, hay un conjunto de críticas que Aron hace en nombre del marxismo de Marx que no hemos podido cubrir aquí. Nos referimos en particular a las que hace al grupo católico progresista de Esprit y a las que dirige al estructuralismo althusseriano. Ello puede ser mejor cubierto en otro artículo con una óptica más claramente centrada en la historia intelectual. Finalmente, entender la forma en que Aron interpreta a Marx y al marxismo parece una clave importante para comprender a un pensamiento que tiene aristas particulares y originales: en tal sentido, queda pendiente a futuro un trabajo conceptual sobre el modo en que Aron relaciona los conceptos de libertad e historia como claves de su ideario liberal-conservador.

\section{Referencias Bibliográficas}

Aron, R. (1939). El concepto de clase del pensamiento sociológico actual. Revista Mexicana de Sociología, 1, 97-108.

Aron, R. (1967). El opio de los intelectuales. (E. Alonso, Trad.). Buenos Aires: Siglo Veinte.

Aron, R. (1969). Los marxismos imaginarios. De Sartre a Althusser (M. Sagrera, Trad.). Caracas: Monte Ávila Editores. Aron, R. (1985a). Estudos politicos (S. Bath, Trad. $2^{\circ}$ ed.). Brasilia: Editora Universidade de Brasilia.

Aron, R. (1985b). Liberdade: Liberal ou Libertária? (S. Bath, Trad.). En Estudos politicos (2ed.) (pp. 263-297). Brasilia: Editora Universidade de Brasilia.

Aron, R. (1985c). Macht, Power, Puissance: Prosa Democrática ou Poesia Demoníaca? (S. Bath, Trad.). En Estudos politicos (2 ${ }^{\circ}$ ed.), (pp. 203-243) Brasilia: Editora Universidade de Brasilia.

Aron, R. (1990). Memoirs. New York: Holmes \& Meier Publishers.

Aron, R. (2001). Le spectateur engagé: entretiens avec Jean-Louis Missika et Dominique Wolton. Paris: Éditions de Fallois - Livre de Poche.

Aron, R. (2002). The dawn of universal history: selected essays. New York: Basic Books.

Aron, R. (2010a). Mémoires (Édition intégrale). Paris: Robert Laffont. 
Aron, R. (2010b). El marxismo de Marx, editado por Jean-Claude Casanova y Christian Bachelier (A. A. Negrotto, Trad.). Madrid: Siglo XXI.

Aron, R. (2014a). Essai sur les libertés. Paris: Calmann-Lévy.

Aron, R. (2014b). Les Désillusions du progrès. Paris: Calmann-Lévy.

Bigo, P. (1966). Marxismo y humanismo: Introducción a la obra económica de Karl Marx (J. Marchal, Trad., 2 ed.). Madrid: Zyx.

Calvez, J.-Y. (1964). El pensamiento de Carlos Marx (F. Trapero, Trad., 4ª ed.). Madrid: Taurus.

Charle, L. (2009). El nacimiento de los intelectuales. Buenos Aires: Nueva Visión.

Cohen-Solal, A. (1990). Sartre (O. L. Molina, Trad.). Barcelona: Edhasa.

de Beauvoir, S. (1963).J. P. Sartre versus Merleau-Ponty. Buenos Aires: Siglo Veinte.

Denord, F. (2009). French Neoliberalism and Its Divisions. From the Colloque Walter Lippmann to the Fifth Republic. En P. Mirowski \& D. Plehwe (Eds.), The road from Mont Pèlerin: the making of the neoliberal thought collective (pp. 45-67). Cambridge, Mass.: Harvard University Press.

Dosse, F. (2007). La marcha de las ideas: historia de los intelectuales, historia intelectual. Valencia: Universitat de València.

Engels, F. (1977). La subversión de la ciencia por el señor Eugen Dubring: Anti-Dubring (S. Manuel, Trad.). México, D. F.: Grijalbo.

Gurvitch, G. (1961). La sociologie de Karl Marx. Paris: Centre de Documentation Universitaire.

Gurvitch, G. (1971). Dialéctica y Sociología (J. R. Capella, Trad. $2^{\circ}$ ed.). Madrid: Alianza.

Kojève, A. (1969). Introduction to the reading of Hegel; lectures on the phenomenology of spirit. New York: Basic Books.

Lottman, H. (1994). La Rive Gauche: la élite intelectual y politica en Francia entre 1935 y 1950 (J. Martínez Guerricabeitia, Trad.). Barcelona: Tusquets.

Lukács, G. (1970). Historia y Conciencia de Clase. La Habana: Ciencias Sociales.

Mahoney, D. J. (2003). Aron, Marx, and Marxism. European Journal of Political Theory, 2(4), 415-427.

Mesure, S. (2015). Aron and Marxism: The Aronian Interpretation of Marx. En J. Colen \& E. Dutartre-Michaut (Eds.), The companion to Raymond Aron (pp. 217-230). New York: Palgrave Macmillan.

Nash, G. H. (1987). La rebelión conservadora en los Estados Unidos. Buenos Aires: Grupo Editor Latinoamericano.

Reinhoudt, J. \& Audier, S. (2018). The Walter Lippmann Colloquium. The Birth of Neo-Liberalism. Cham: Palgrave Macmillan.

Sartre, J. -P. (1973). Situaciones 8. Alrededor del 68 (E. G. Kieffer, Trad.). Buenos Aires: Losada.

Schumpeter, J. A. (1996). Capitalismo, Socialismo y Democracia. Barcelona: Folio.

Sirinelli, J.-F., y Ory, P. (2007). Los intelectuales en Francia, del caso Dreyfus a nuestros dias (Miñano, Evelio ed.). Valencia: Publicaciones de la Universitat de Valencia.

Traverso, E. (2001). El totalitarismo. Historia de un debate (M. Gurian, Trad.). Buenos Aires: Eudeba.

Weil, E. (1996). Hegel y el estado. Buenos Aires: Leviatán.

Winock, M. (2010). El siglo de los intelectuales (A. Herrera, Trad.). Barcelona: Edhasa.

\section{Notas}

1 En el prefacio de la edición norteamericana de las memorias de Aron (1990), Henry Kissinger se declara discípulo del filósofo francés, pero lo muestra como un anticomunista carente de matices. Por supuesto, Aron era un ferviente anticomunista, pero, como se tratará de mostrar aquí, lo era de un modo particular: al socialismo realmente existente le oponía no solo las ideas liberales sino también las del propio Marx.

2 Por razones de espacio hemos decidido dejar el tratamiento de las críticas a Althusser y Mounier para un futuro trabajo en torno a las polémicas con el pensamiento estructuralista y el catolicismo progresista. 
3 En este sentido, sería necesario un trabajo que tomara como principales referencias al Ensayo sobre las libertades, Las desilusiones del Progreso y varios otros textos menores (Aron, 2014a; 2014b; 1985a).

4 La interpretación del Marx joven corrigiendo al Marx maduro, propia de los jesuitas Jean-Yves Calvez (1964) y Pierre Bigo (1966), es criticada de forma recurrente, por ejemplo en Aron (2010b, pp. 432-438, 467-470 y 592-594).

5 Para el lector más interesado en la marxistología que en el pensamiento de Aron, estos pasajes, junto con los capítulos XIV y XV (pp. 467-541 de la edición en español) son centrales.

6 Aron (1969) retoma esta discusión en su ensayo sobre la Crítica de la Razón Dialéctica de Sartre y en sus textos sobre relaciones internacionales (ver, por ejemplo, los ensayos de Aron, 2002).

7 En el Anti-Dhuring, Engels insiste en que el despliegue historia puede acelerarse por medio de la violencia, pero no detenerse. Para algunos marxistas esta obra de Engels no debería ser tomada en cuenta; pero para Aron (2010b, p. 550) sí, porque "Engels leyó todo el libro a Marx y, de acuerdo con lo que él afirma y lo que surge de las cartas de Marx, éste último lo aprobó”. El análisis de Engels (1977) ocupa todo el cap. XVI y, de acuerdo con Aron, su estudio es esencial, porque sintetiza el materialismo dialéctico que se convirtió en ideología oficial en la Unión Soviética.

8 El autor lo explica de la siguiente manera: "El comunismo se desarrolló a partir de una doctrina económica y política, en una época en que declinaban la vitalidad espiritual y la autoridad de las Iglesias. Los ardores que, en otros tiempos, hubieran podido expresarse en creencias propiamente religiosas, tomaron por objeto la acción política. El socialismo apareció menos como una técnica aplicable a la gestión (...) que como una ruptura con la desdicha secular de los hombres" (Aron, 1967, p. 258).

9 En Los marxismos imaginarios, Aron (1969, p. 14) hará lo opuesto: disculpa a Merleau-Ponty, "muerto antes de haber terminado su obra, se alejaba al parecer de estas controversias histórico-políticas para remontarse a las cuestiones supremas de la filosofía (...)" y se ensaña con un "Sartre [que] ha permanecido fiel a sí mismo [y] consagra centenares y centenares de páginas a una dialéctica (...) que no tiene nada en común con el marxismo”.

10 Merleau-Ponty se alejó de la política tras la guerra de Corea, pero en 1955 en Las aventuras de la dialéctica dedicó un capítulo a criticar las posiciones sartreanas, lo que le valió críticas de Les Temps Modernes en general y de Simone de Beauvoir en particular. El libro de Merleau-Ponty era, en parte, respuesta al ensayo de Sartre "Los comunistas y la paz", publicado entre 1952 y 1953. Simone de Beauvoir contestó con un duro texto, Merleau-Ponty et le pseudo-sartrisme, de 1955, que se tradujo como Sartre versus Merleau-Ponty (de Beauvoir, 1963). 